\title{
LETTER
}

\section{A depth coincidence between the lanthanide tetrad effect maximum and the oxic/anoxic interface at the Cariaco Trench off the Venezuelan coast}

\author{
AKIMASA Masuda, ${ }^{1 *}$ JUNJI ShIMOdA ${ }^{1}$ and YoshinIRo IKEUCHI ${ }^{2}$ \\ ${ }^{1}$ Department of Chemistry, University of Electro-Communications, Chofu, Tokyo 182-0021, Japan \\ 2Japan Chemical Analysis Center, Inage-ku, Chiba 263-0002, Japan
}

(Received November 28, 1997; Accepted February 25, 1998)

\begin{abstract}
Under the highly stagnant condition at the Cariaco Trench, the lanthanide tetrad effect takes place abruptly within an extremely narrow depth range. The lanthanide tetrad effect maximum at the Cariaco Trench is observed at $256 \mathrm{~m}$ coinciding with its oxic/anoxic interface at $280 \mathrm{~m}$. It is also interesting that the maximum value of the lanthanide tetrad effect at this trench is substantially the same as that in ordinary open ocean.
\end{abstract}

\section{INTRODUCTION}

Systematic studies on physico-chemical properties of lanthanides led to a discovery of the lanthanide tetrad effect (Fidelis and Siekierski, 1966; Peppard et al., 1969; Jørgensen, 1970; Nugent, 1970).

Masuda and Ikeuchi (1979) were the first to announce the discovery of the lanthanide tetrad effect in seawater. Further, Masuda et al. (1987) recognized the common occurrence of two mutually conjugate types, $\mathrm{W}$ and $\mathrm{M}$, of this phenomenon in nature. Kawabe (1992) has not only improved the refined spin-pairing energy theory presented by Jørgensen (1962) to elucidate the effect in question, but also pointed out the occurrence of this effect in eight reference rocks (Kawabe, 1995). Masuda (1995) proposed a model to explain the effect in terms of major directions of $\mathrm{f}$ electron clouds and their steric symmetry. McClennan has criticized this effect (McClennan, 1994) but his comments are not sound, because they involve low quality data and theoretically rest on the third ionization potential.

It can be expected that the extent of the lanthanide tetrad effect varies systematically with depth in marine environments. For this purpose, it is indispensable to invent in advance a quantitative index to indicate the degree of the lanthanide tetrad effect.

As a result of the lanthanide tetrad effect, 15 elements including lanthanum are divided into four groups, each comprising 4 elements. The lanthanide tetrad effect is an intra-tetrad fractionation. Since there are four groups, four curves arise each encompassing four adjacent lanthanides. However, $\mathrm{Ce}$ and $\mathrm{Eu}$ are omitted except for rather special conditions.

\section{Mathematical}

Minami and Masuda (1997) have developed a mathematical method applicable ideally to the fifteen lanthanide members with same weights. This formulation, however, is valid under the condition that all the elements concerned are determined with similar good precisions. In cases

*Correspondence should be addressed to: 449 Shimo-Yasumatsu, Tokorozawa, Saitama 359-0024, Japan 
where $\mathrm{La}, \mathrm{Nd}, \mathrm{Sm}, \mathrm{Gd}, \mathrm{Dy}, \mathrm{Er}, \mathrm{Yb}$ and $\mathrm{Lu}$ are determined with sufficiently high precisions, the method proposed by Masuda et al. (1994) is pragmatic.

When the intra-tetrad fractionation is approximated by a quadratic function $y=a x^{2}+b x+c$, one can use either of two parameters to quantitatively indicate the effect under consideration. For one of them, a quadratic coefficient $a$ can be used. We can use the aberration extremum (ABEX) within the tetrad group for the other index. Mathematically, both of these parameters are "equivalent", but the ABEX value is convenient for practical visual use. The ABEX value for light REE is designated as ABEXEL. Needless to say, negative ABEXEL values correspond to W-type tetrad effect, while positive ones to M-type tetrad effect. Two cases of mathematical analyses to evaluate ABEXEL are shown in Fig. 1. For a detailed mathematical treatment, the readers are referred to the paper by Masuda et al. (1994).
Thus far, we have obtained the depth profiles of the lanthanide tetrad effect in North Pacific, Indian and Southern Oceans (Masuda and Shimoda, 1996; Masuda and Shimoda, 1997a, b, c), disclosing the potential for the lanthanide tetrad effect as a new oceanographic tool. However, the specific case reported here is one of the most interesting studies of the depth profiles of the lanthanide tetrad effect from the viewpoint of marine chemistry.

\section{The Cariaco Trench}

The Cariaco Trench is located at $10^{\circ} 40^{\prime} \mathrm{N}$, $65^{\circ} 35^{\prime} \mathrm{W}$, and its maximum depth is $1400 \mathrm{~m}$. The waters above sill depth (146 m) exchange freely with the open Caribbean Sea. According to De Baar et al. (1988) a strong pycnocline is developed at 150-300 m depth. These authors carried out an interesting oceanographic investigation of this trench, paying a special attention to the oxic/ anoxic interface. The distribution of Mn has shown

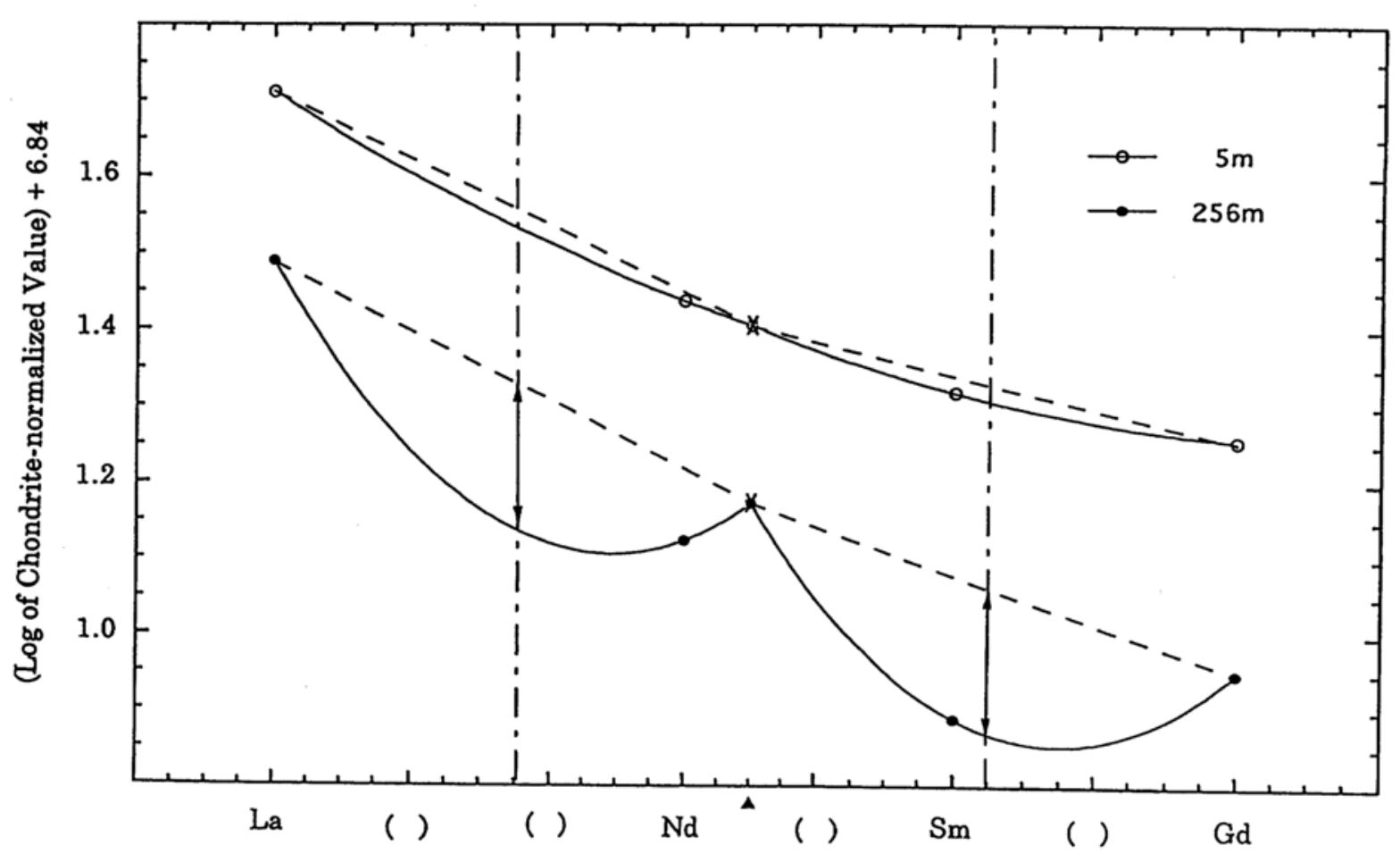

Fig. 1. Evaluation of ABEXEL values for two depths. Arrows indicate ABEXEL value for $256 \mathrm{~m}$, and triangles and crosses the position of cusp point. 
a sharp discontinuity at $280 \mathrm{~m}$. The abundance data for lanthanides also exhibited discontinuities around $280 \mathrm{~m}$. The condition at the Cariaco Trench resembles that of an "experiment" in a vertically nearly closed stagnant water column ranging from $150 \mathrm{~m}$ (sill depth) to $1400 \mathrm{~m}$ (bottom).

\section{Results AND Discussion}

The results of our calculation about the lanthanide effect for the data presented by De Baar
Table 1. ABEXEL values at the Cariaco Trench

\begin{tabular}{cccccc}
\hline Depth $(\mathrm{m})$ & ABEXEL & & Depth $(\mathrm{m})$ & ABEXEL \\
\cline { 1 - 2 } \cline { 5 - 6 } 5 & -0.023 & & 302 & -0.098 \\
50 & -0.080 & & 327 & -0.082 \\
150 & -0.082 & & 337 & -0.061 \\
256 & -0.192 & & 496 & -0.137 \\
278 & -0.142 & & 697 & -0.104 \\
288 & -0.150 & & 1,395 & -0.109 \\
292 & -0.097 & & \\
\hline
\end{tabular}

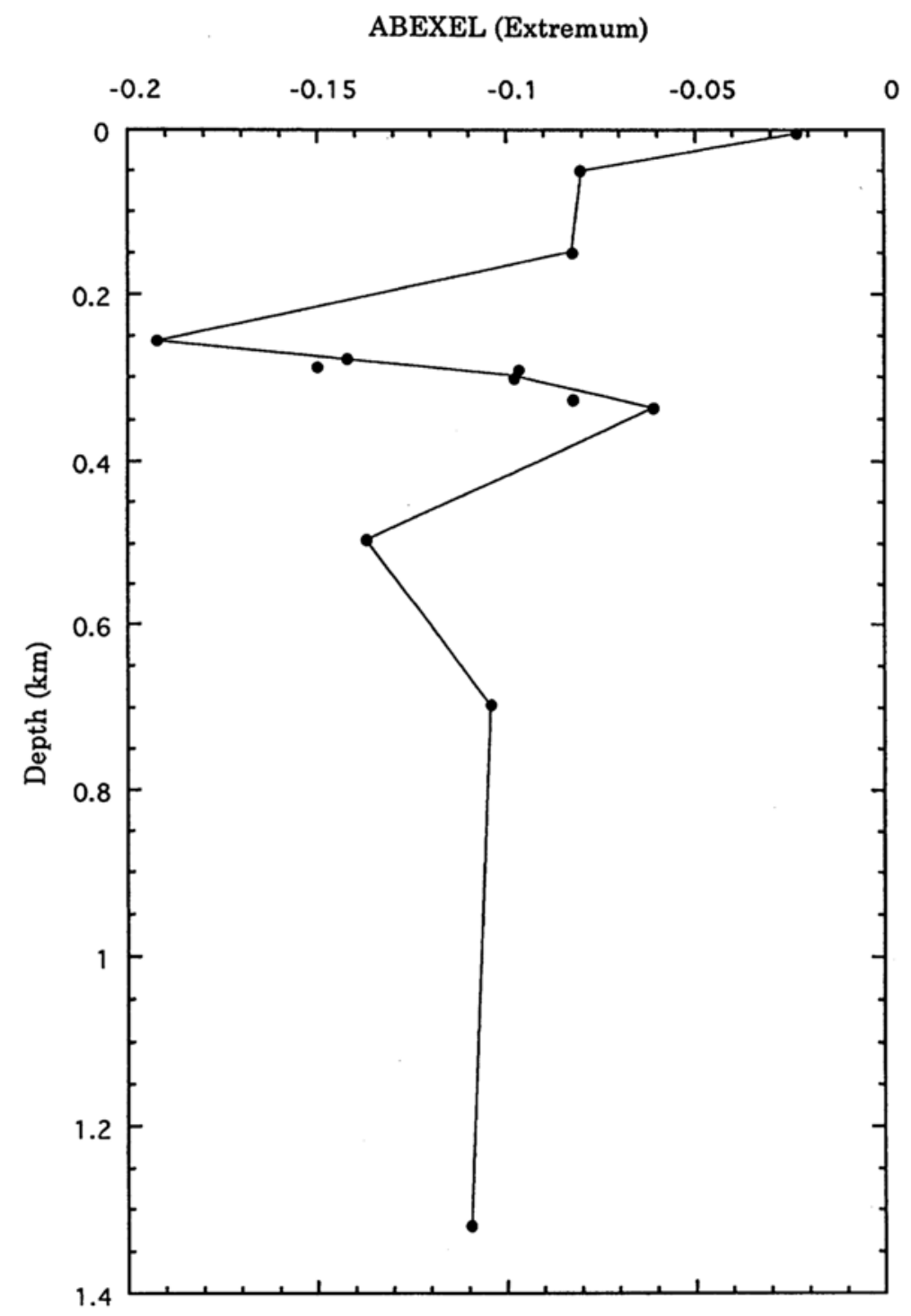

Fig. 2. Depth profile of ABEXEL value (degree of intra-tetrad fractionation for light REE). 

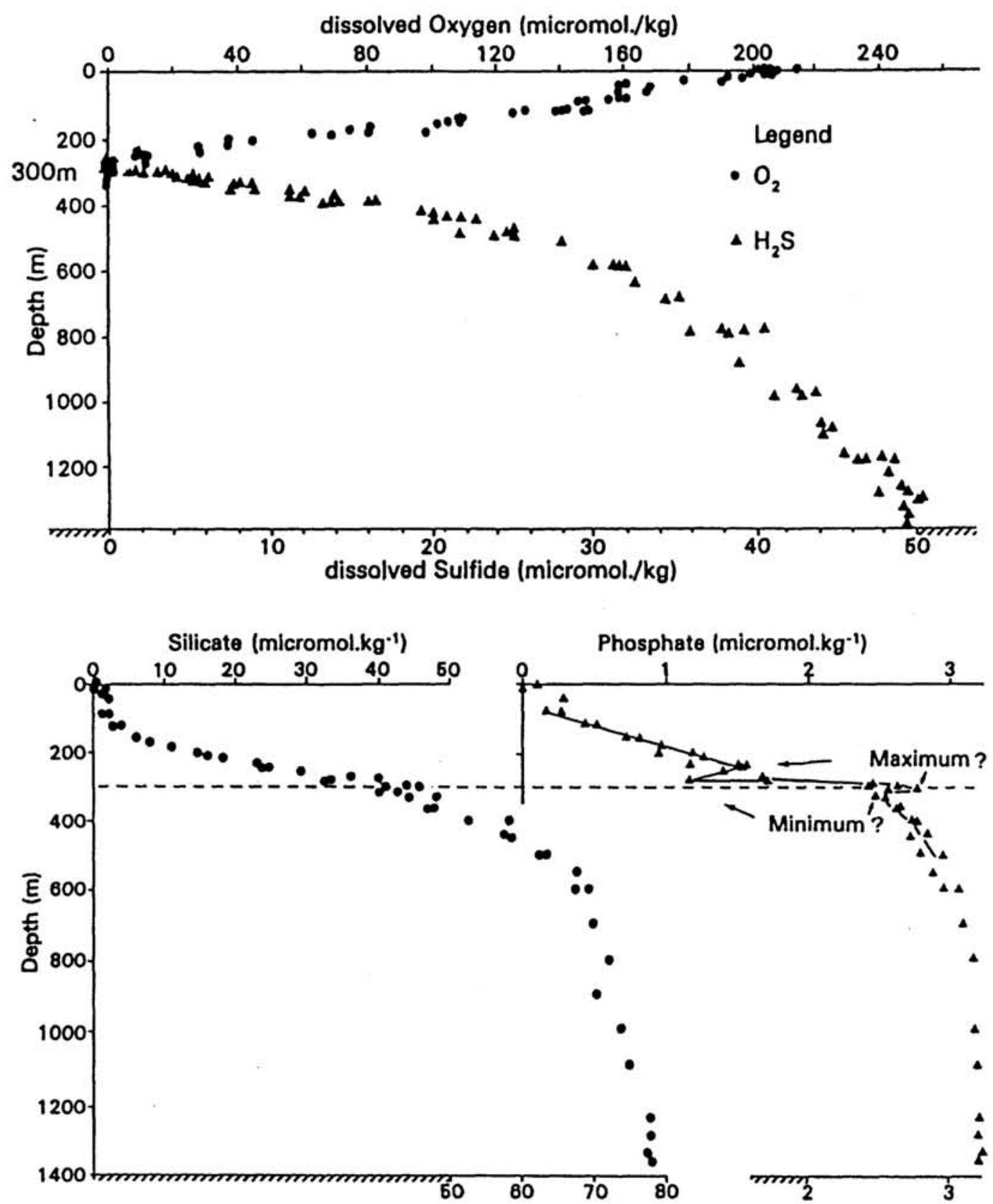

Fig. 3. Depth profiles of dissolved oxygen, phosphate and silicate (courtesy of De Baar et al., 1988).

et al. (1988) are presented in Table 1 and Fig. 2 . For abundance normalization, Leedey chondrite is used (Masuda et al., 1973). Figure 3 (after De Baar et al., 1988) shows a very rapid decrease of dissolved oxygen down to $280 \mathrm{~m}$. The original authors showed that the oxic-anoxic boundary (280 m) corresponds to sharp discontinuities of vertical profiles of particulate $\mathrm{Mn}$ and $\mathrm{Fe}$.

It can be seen (Fig. 2) that a maximum of negative ABEXEL (n-ABEXEL) is observed at $256 \mathrm{~m}$ and there is a rapid decrease of n-ABEXEL from $0.192(256 \mathrm{~m})$ to $0.061(337 \mathrm{~m})$. A large 
ABEXEL change of 0.131 in a short depth interval of $80 \mathrm{~m}$ is notable. At the same time, scrutiny of diagram (Fig. 3) presented by these authors for phosphate indicates small irregularities in phosphate content between 242 and $325 \mathrm{~m}$. There appear to be two small maxima and two small minima in this short depth interval. The Si content does not show such a fine structure.

There appears to be another maximum of nABEXEL at $496 \mathrm{~m}$. We cannot rule out the possibility that this apparent maximum might have been caused by a fortuitous error in measurement. However, a small maximum of dissolved $\mathrm{Mn}$ at $480 \mathrm{~m}$ (Fig. 8 in the original), which may be related with the broad sea floor around $500 \mathrm{~m}$ surrounding the trench, draws attention.

It is interesting that the maximum of $n$ ABEXEL is 0.192 at $256 \mathrm{~m}$, because this value of 0.192 is within the range of maximum values, $0.181-0.2055$, for the other ordinary open oceans (Masuda and Shimoda, 1997b), in spite of the difference in absolute depth between the Cariaco Trench $(1400 \mathrm{~m})$ and the ordinary open ocean (about $5 \mathrm{~km}$ ). Further it may be worth pointing out that the depth of $256 \mathrm{~m}$ is $1 / 5.5$ of the total depth.

Table 1 shows that ABEXEL values at 50 and $150 \mathrm{~m}$ are around -0.080 . This value reflects the value for the upper surface layer of the open Caribbean Sea. The value of -0.023 at $5 \mathrm{~m}$ implies the highest immaturity of the water mass concerned, indicating the contribution of runoff from the continental terrain. This is related with the fact that the current activity is weak at this area as this site is close to the land (Venezuela) and surrounded by islets. On the other hand, it also merits attention that the n-ABEXEL values at 695 and $1395 \mathrm{~m}$ are 0.104 and 0.109 , respectively, being nearly invariable at within this depth range. This may suggest resetting of the tetrad effect below the stringent pycnocline. Obviously, in comparison with these levels, those for 327 and $337 \mathrm{~m}$ are slightly positive.

De Baar et al. (1988) proposed a model for vertical transport of strictly trivalent REE along with the cycling of $\mathrm{Mn}$ (or $\mathrm{Fe}$ ) at the oxic/anoxic interface. The model (cf., Fig. 13 in De Baar et al., 1988) of scavenging and desorption of REE in association with the cycling of $\mathrm{Mn}$ (or $\mathrm{Fe}$ ) at the oxic/anoxic interface can be extended to explain the lanthanide tetrad effect profile we observed. Besides, it may be recalled that the n-ABEXEL features around the oxic/anoxic interface appears to be related with the phosphate subtleties around $242 \sim 325 \mathrm{~m}$. That is, a certain unidentified biological or biogenic factor can be an additional factor affecting the depth profile of lanthanide tetrad effect. The speciation of phosphate in seawater could possibly be a clue to the factor in question.

The results of this analysis indicate that the aqueous oxic/anoxic interface offers one of the most reactive chemical circumstances to promote the lanthanide tetrad effect. The lanthanide tetrad phenomenon, however, can be also developed in the oxic condition like in the Antarctic Ocean (German et al., 1995; Masuda and Shimoda, 1997c).

According to our evaluation, the ABEXEL values are the most sensitive to the measurement errors of $\mathrm{Nd}$ and $\mathrm{Sm}$. If $\pm 1 \%$ errors are assumed for both of $\mathrm{Nd}$ and $\mathrm{Sm}$, they yield maximum uncertainties of \pm 0.011 for the resulting ABEXEL values. In this communication we could not discuss ABEX-3 and ABEX-4 (Masuda and Shimoda, 1997a), because the abundance data for heavy REE are lacking at a considerable number of depth.

Acknowledgments-We are grateful to Prof. Kazuo Yamasaki for his continued interest in the subject dealt with here and to Prof. Henry Elderfield, Cambridge University, for his permission to use diagrams in GCA 52.

\section{REFERENCES}

De Baar, H. J. W., German, C. R., Elderfield, H. and Van Gaans, P. (1988) Rare earth element distributions in anoxic waters of the Cariaco Trench. Geochim. Cosmochim. Acta 52, 1203-1219.

Fidelis, I. K. and Siekierski, S. (1966) The regularities in stability constants of some rare earth complexes. J. Inorg. Nucl. Chem. 28, 185-188.

German, C. R., Masuzawa, T., Greaves, M. J., 
Elderfield, H. and Edmond, J. M. (1995) Dissolved rare earth elements in the Southern Ocean: Cerium oxidation and the influence of hydrography. Geochim. Cosmochim. Acta 59, 1551-1558.

Jørgensen, C. K. (1962) Electron transfer spectra of lanthanide complexes. Mol. Phys. 5, 271-277.

Jørgensen, C. K. (1970) The "tetrad effect" of Peppard is a variation of the nephelauxetic ratio in the third decimal. J. Inorg. Nucl. Chem. 32, 3127-3128.

Kawabe, I. (1992) Lanthanide tetrad effect in the $\mathrm{Ln}^{3+}$ ionic radii and refined spin-pairing energy theory. Geochem. J. 26, 309-335.

Kawabe, I. (1995) Tetrad effects and fine structures of REE abundance patterns of granitic and rhyolitic rocks: ICP-AES determinations of REE and $\mathrm{Y}$ in eight GSJ reference rocks. Geochem. J. 29, 213-230.

Masuda, A. (1995) The third ionization potentials of lanthanides and major orientations of $4 \mathrm{f}$ orbital clouds. Proc. Jpn. Acad. 71B, 165-169.

Masuda, A. and Ikeuchi, Y. (1979) Lanthanide tetrad effect observed in marine environment. Geochem. J. 13, 19-22.

Masuda, A. and Shimoda, J. (1996) Lanthanide tetrad effect and epsilon Nd to characterize two water column profiles in the western North Pacific. Proc. Jpn. Acad. 72B, 202-207.

Masuda, A. and Shimoda, J. (1997a) Separate lanthanide tetrad effects in two seawater columns from the North West Pacific: A peculiarity of the fourth lanthanide tetrad under a certain condition. Proc. Jpn. Acad. 73B, 39-43.

Masuda, A. and Shimoda, J. (1997b) Depth profiles of lanthanide tetrad effect in the western Indian Ocean and their implications. Proc. Jpn. Acad. 73B, 187-
191.

Masuda, A. and Shimoda, J. (1997c) Unique characteristics of the depth profile of lanthanide tetrad effect observed in the Southern Ocean. Proc. Jpn. Acad. 73B, 195-200.

Masuda, A., Nakamura, N. and Tanaka, T. (1973) Fine structures of mutually normalized rare earth patterns of chondrites. Geochim. Cosmochim. Acta 37, 239248.

Masuda, A., Kawakami, O., Dohmoto, Y. and Takenaka, T. (1987) Lanthanide tetrad effects in nature: two mutually opposite types, $\mathrm{W}$ and $\mathrm{M}$. Geochem. J. 21, 119-124.

Masuda, A., Matsuda, N., Minami, M. and Yamamoto, H. (1994) Approximate estimation of the degree of lanthanide tetrad effect from precise but partially void data measured by isotope dilution and an electron configuration model to explain the tetrad phenomenon. Proc. Jpn. Acad. 70B, 169-174.

McClennan, S. M. (1994) Rare earth element geochemistry and the "tetrad" effect. Geochim. Cosmochim. Acta 58, 2025-2033.

Minami, M. and Masuda, A. (1997) Approximate estimation of the degree of lanthanide tetrad effect from the data potentially involving all lanthanides. Geochem. J. 31, 125-133.

Nugent, L. J. (1970) Theory of the tetrad effect in the lanthanide (III) and actinide (III) series. J. Inorg. Nucl. Chem. 32, 3485-3491.

Peppard, D. F., Mason, G. W. and Lewey, S. (1969) A tetrad effect in the liquid-liquid extraction ordering of lanthanides (III). J. Inorg. Nucl. Chem. 31, 22712272. 